\section{Commentary: Late attrition in Norwood populations: Kicking the can down the road?}

\author{
David J. Barron, FRCS(CT), and \\ Anusha Jegatheeswaran, MD, PhD, FRCSC
}

We continue to learn from the unique experience of the Children's Hospital of Philadelphia's (CHOP) analysis of their Norwood program for hypoplastic left heart syndrome, with the notable finding that the attrition between stage 2 and stage 3 has remained unchanged over the past 30 years. ${ }^{1}$ It is an unexpected finding given the remarkable progress that has been made over this same time period. The dramatic improvements seen in stage 1 and interstage 1 or 2 outcomes have still meant better overall survival for this population. So why has attrition after stage 2 remained constant in the CHOP series? The most likely reason is that the successes in early management have led to survival of some of the most fragile children, those who would not previously have survived. However, ventricular dysfunction, persistent atrioventricular (AV) valve regurgitation and poor pulmonary vasculature continue to be a problem beyond stage 2 . Unfortunately, this study is unable to answer this key question because there are no data on ventricular function or $\mathrm{AV}$ valve function-nor on the premorbid condition of the patients who died. However, the fact that AV valve intervention and prolonged length of stay at stage 2 were strongly linked with poor outcome suggest these are surrogate markers for this fragile patient group. Hence, the successes in early outcomes may have simply kicked the can down the road in terms of managing these challenging problems. On the positive side, the multivariate risk model does show that some of the tenacious risks of neonatal repair, such as low

\footnotetext{
From the Division of Cardiovascular Surgery, Department of Surgery, Hospital for Sick Children, Toronto, Ontario, Canada.

Disclosures: The authors reported no conflicts of interest.

The Journal policy requires editors and reviewers to disclose conflicts of interest and to decline handling or reviewing manuscripts for which they may have a conflict of interest. The editors and reviewers of this article have no conflicts of interest.

Received for publication Nov 16, 2020 ; revisions received Nov 16, 2020; accepted for publication Nov 17, 2020; available ahead of print Nov 24, 2020.

Address for reprints: David J. Barron, FRCS(CT), Division of Cardiovascular Surgery, Department of Surgery, Hospital for Sick Children, 555 University Ave, Toronto, Ontario M5G 1X8, Canada (E-mail: david.barron@sickkids.ca).

J Thorac Cardiovasc Surg 2021;162:398-9

0022-5223/ $\$ 36.00$

Crown Copyright (C) 2020 Published by Elsevier Inc. on behalf of The American Association for Thoracic Surgery

https://doi.org/10.1016/j.jtcvs.2020.11.070
}

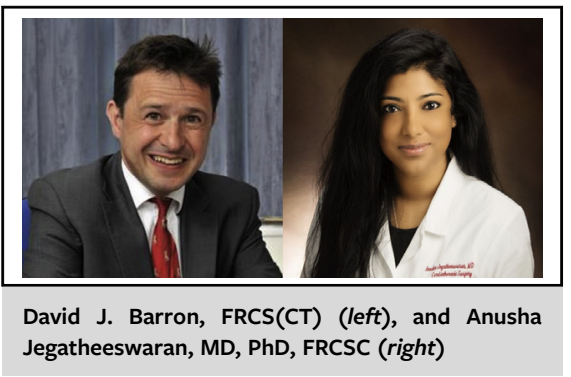

\begin{abstract}
CENTRAL MESSAGE
Attrition after stage 2 Norwood

has not changed in 30 years.

Improved neonatal outcomes

may have created a fragile sub-

population of patients who did

not survive in earlier eras and

remain at risk.
\end{abstract}

weight and prematurity, have now ceased to be risk factors once these patients are through the stage 2 period.

Although this dataset appears to be very rich, the analysis was relatively limited and much of the clinical data were not available. It would have been extremely informative to review the results of a competing risks analysis with time zero as discharge from the hospital after stage 2 and end states, including time-related transition to Fontan, remaining alive without any additional procedures, and transition to a state of attrition. Review of the features associated with successful transition to Fontan would have also provided a deeper understanding of these patients. It would also be particularly important to have a better understanding of the completeness of follow-up because $5 \%$ of patients were missing.

The other striking observation was the association of the right ventricle to pulmonary artery (RV-PA) conduit Norwood with late attrition. This could reflect the influence of the ventriculotomy on long-term function, but the lack of detailed echocardiography/hemodynamic data means we are unable to clarify this. Equally, the finding could reflect that the RV-PA conduit has greatest influence on survival in the highest-risk neonatal patients and that late attrition is amongst those patients with intrinsically poorer RV and $\mathrm{AV}$ valve function; in other words, kicking the can down the road again.

Any single-center study is inevitably hampered by institutional bias, which can be difficult to control for: CHOP has remained a strong proponent of the Blalock-Taussig 
shunt with only $17.5 \%$ of this cohort having an RV-PA conduit. They have done so with good reason because their outcomes have been outstanding, but it remains unclear from this study what criteria were used to favor each strategy and whether the groups are truly comparable. Furthermore, the high neonatal mortality in the early $\operatorname{eras}^{2}$ would have been exclusively with the Blalock-Taussig shunt, so the surviving population may have been self-selected as the more robust survivors.

Multicenter studies are more able to mitigate the effects of institutional practice, with the Congenital Heart Surgeons' Society study ${ }^{3}$ suggesting a continued survival benefit of the RV-PA conduit group well beyond this stage 2 to stage 3 period, and the Single Ventricle Reconstruction Trial showing no increased attrition. ${ }^{4}$

Nevertheless, the fact that the greatest risk appears to be during the first 13 months after stage 2 should encourage us to focus more on this age group and try to duplicate some of the successes of interstage monitoring after stage 1 in preempting clinical deterioration.

\section{References}

1. Lawrence KM, Ittenbach RF, Hunt ML, Kaplinski M, Ravishankar C, Rychik J, et al. Attrition between the superior cavopulmonary connection and the Fontan procedure in hypoplastic left heart syndrome. J Thorac Cardiovasc Surg. 2021; 162:385-93.

2. Mascio CE, Irons ML, Ittenbach RF, Gaynor JW, Fuller SM, Kaplinski M, et al Thirty years and 1663 consecutive Norwood procedures: has survival plateaued? J Thorac Cardiovasc Surg. 2019;158:220-9.

3. Wilder TJ, McCrindle BW, Phillips AB, Blackstone EH, Rajeswaran J, Williams WG, et al. Survival and right ventricular performance for matched children after stage-1 Norwood: modified Blalock-Taussig shunt versus rightventricle-to-pulmonary-artery conduit. J Thorac Cardiovasc Surg. 2015;150: 1440-50.

4. Newburger JW, Sleeper LA, Gaynor JW, Hollenbeck-Pringle D, Frommelt PC, Li JS, et al. Transplant-free survival and interventions at 6 years in the SVR trial. Circulation. 2018;137:2246-53. 